\title{
Diagnostic Accuracy of Serum Procalcitonin (PCT) as an Early Biomarker of Neonatal Sepsis using Blood Culture as Gold Standard
}

\author{
Aisha Habib, Saba Raza, Usman Ali, Adnan Mustafa Zubairi and Erum Salim \\ Department of Chemical Pathology, Ziauddin Medical University and Hospital, Karachi, Pakistan
}

\begin{abstract}
Objective: To ascertain the diagnostic accuracy of serum PCT as an early biomarker of neonatal sepsis using blood culture as gold standard, so that the condition could be diagnosed and managed early to prevent and reduce morbidity and mortality in neonates.

Study Design: Cross-sectional study.

Place and Duration of Study: Dr. Ziauddin University Hospital, Karachi, from March 2019 to December 2019.

Methodology: A total of 171 neonates, 1-29 days of age, presented with clinical diagnosis of neonatal sepsis, were included in this study. Patients' data regarding age, gender, birth weight, prematurity and premature rupture of membranes (PROM) were collected. Blood cultures were performed in Microbiology Department; and Serum PCT was analyzed on Electrochemiluminescence Immunnoassay Analyzer (Cobas e601). Diagnostic accuracy, including sensitivity, specificity, positive predictive value (PPV) and negative predictive value (NPV) of PCT were calculated with contingency tables using blood culture findings as gold standard.

Results: Out of 171 clinically diagnosed cases of neonatal sepsis, 86 (50.3\%) were confirmed as having neonatal sepsis (blood culture positive). There was a significant difference in serum PCT levels in both the groups. The sensitivity of PCT was $97.7 \%$; specificity 70.6\%; PPV 77.1; NPV 96.8\%; likelihood ratio of a positive test (LR+ve) 3.32; likelihood ratio of a negative test (LR ve) 0.03 , and cumulative diagnostic accuracy of PCT $84.2 \%$.

Conclusion: PCT is a very useful biomarker for the early diagnosis of neonatal sepsis, showing $84.2 \%$ diagnostic accuracy. Thus PCT can help in making early clinical decisions regarding management of patients.
\end{abstract}

Key Words: Diagnostic accuracy, PCT, Neonatal sepsis.

How to cite this article: Habib A, Raza S, Ali U, Zubairi AM, Salim E. Diagnostic Accuracy of Serum Procalcitonin (PCT) as an Early Biomarker of Neonatal Sepsis using Blood Culture as Gold Standard. J Coll Physicians Surg Pak 2021; 31(04):383-387.

\section{INTRODUCTION}

Sepsis is defined as "life-threatening organ dysfunction, caused by a dysregulated host response to infection". ${ }^{1}$ It is a spectrum of disease that ranges from minor signs and symptoms to organ dysfunction (severesepsis) and shock. The mechanism of sepsis is complex. Macrophages phagocytose bacteria and produce a range of proinflammatory cytokines, which initiate the innate immune system's response to the bacterial pathogen and produces interleukin (IL)-1 $\beta$, tumor necrosis factor (TNF) and IL-6, which leads to clinical signs of sepsis. ${ }^{2,3}$ Neonatal sepsis can be classified on the basis of time of onset into early onset (within one week of life) and late onset (after one week). ${ }^{4 \cdot 6}$

Correspondence to: Dr. Aisha Habib, Department of Chemical Pathology, Ziauddin Medical University and Hospital, Karachi, Pakistan

E-mail: aishahabib2467@gmail.com

Received: November 13, 2020; Revised: March 06, 2021; Accepted: March 16, 2021

DOI: https://doi.org/10.29271/jcpsp.2021.04.383
Globally, around 130 million children are born per year, out of which 4 million die before the age of one month. In Pakistan, neonatal mortality rate is very high i.e. about 49 per 1000 live births. Sepsis accounts for $36 \%$ deaths in newborns. ${ }^{7}$ Prevalence of neonatal sepsis in Pakistan is 29.25\%. ${ }^{8}$

As the immune system of neonates is not fully developed, it becomes very difficult to differentiate sepsis from systemic inflammation clinically. The laboratory tests, which play an important role in its diagnosis are: Absolute neutrophil count, blood culture, C-reactive protein (CRP), IL-6, IL-8 and lactate. ${ }^{9,10}$

To date, blood culture is the gold standard test for diagnosing sepsis, but it has some inherent limitations. It takes at least three or five days to be decisive and can be mistakenly negative because antibiotics are initiated empirically before collection and a well-developed microbiology laboratory is required. To overcome these problems, certain newer markers including PCT are now being considered for the diagnosis of sepsis. ${ }^{11}$

Pre-procalcitonin is synthesised from thyroid $C$ cells and this peptide is then transformed into procalcitonin by endopepti- 
dase cleavage under normal homeostasis. PCT is 116 amino acids chain protein, its half-life is 20-24 hours. In sepsis, macrophages and monocytes of liver are responsible for its synthesis. PCT causes chemotaxis of monocytes, which leads to release of cytokines. ${ }^{12}$ Its levels in healthy people are less than $0.046 \mathrm{ng} / \mathrm{ml} .{ }^{13} \mathrm{PCT}$ levels increases in blood $2-4$ hours after the onset of sepsis; achieve peak within 24 hours, and gradually decreases with proper treatment. ${ }^{14}$

If sepsis in neonates is diagnosed early in the course of disease, it will help in its early empirical treatment; and monitoring, hence, decreasing the complications of disease. Furthermore, it also helps in deciding when to start or stop antibiotic therapy making it a cost effective option as well.

The objective of this study wasto determinethe diagnostic effectiveness of PCT as a biomarker for early diagnosis of neonatal sepsis before a final diagnosis was made through blood cultures.

\section{METHODOLOGY}

This cross-sectional study was conducted from March 2019 to December 2019 in the Department of Chemical Pathology, Dr. Ziauddin University Hospital, Karachi. One hundred and seventy-one neonates, aged 1-29 days, admitted in Neonatal Intensive Care Unit (NICU) of Hospital with the clinical suspicion of sepsis and whose blood culture tests were performed, were included in the study. Non-probability consecutive sampling was done. Permission from the Ethical Committee of the Hospital was taken. Parents/guardians of the patients were informed about study purpose and consents were taken. Participant demographic information including age, gestational age, gender, birth weight $(\mathrm{kg})$ were collected through interview, and questionnaire was filled. In addition, other sepsis markers, including CRP level, total leukocyte count (TLC), and platelet (PLT) count were also recorded.

The diagnostic criteria of suspected neonatal sepsis was used for labelling the cases, which includes any two of following: temperature $>38.5^{\circ} \mathrm{C}$ or $<36^{\circ} \mathrm{C}$, increased heart rate above two standard deviations of normal for age, respiratory rate greater than two standard deviations of normal for age, TLC increased or decreasedfor age or ${ }^{~} 10 \%$ immature neutrophils in peripheral blood. Presence of positive blood culture further confirmed the sepsis. ${ }^{5,15}$

Neonates on antibiotics before blood culture, having congenital disorder on examination, evidence of respiratory distress syndrome on chest $x$-ray PA view and those having clinical suspicion of inborn errors of metabolism were excluded from the study.

Blood samples for PCT were collected in serum separating gel tubes and blood culture samples in Bactec bottles. The labelled samples were transported to Chemical Pathology and Microbiology Departments, respectively. Blood samples for estimation of PCT were centrifuged at $2000 \mathrm{~g}$ for $15 \mathrm{~min}$ and serum was separated and stored at $-20^{\circ} \mathrm{C}$ until assayed. Serum PCT was analysed by Roche Elecsys BRAHMS PCT reagent, on electrochemiluminescence automated immunnoassay analyser (Cobas e601). For diagnosis of sepsis, PCT levels $>0.5 \mathrm{ng} / \mathrm{m}$ I was considered as positive. ${ }^{16}$ Evidence of the presence of pathogenic organisms in blood culture was considered as positive blood culture.

Data was entered and analysed using SPSS version 20.0. Kolmogrov-Smimov test was used to check normality of data. As the data were skewed; median values with interquartile ranges (IQR) were reported along with mean and standard deviation for quantitative variables (age, birth weight, gestational age and PCT level) and these variables were compared by Mann-Whitney test between blood culture positive and negative groups. Qualitative variables (gender, low birth weight, prematurity, and PROM) were presented by frequency and percentage. Effect modifiers such as age, gender, birth weight (neonates having birth weight $<2.5 \mathrm{~kg}$ were labelled as low birth weight), prematurity (neonates born before 36 weeks of gestation were labelled as premature), PROM (rupture of membranes $>24$ hours before parturition were labeled as premature rupture of membranes) were addressed through stratification. The $2 \times 2$ tables with $95 \%$ confidence interval were constructed for PCT and blood culture to calculate the sensitivity, specificity, positive predictive value, negative predictive value, and diagnostic accuracy. Receiver operative characteristic (ROC) curve was plotted for PCT, CRP, TLC, PLT and area under the curve (AUC) calculated and optimal cut-off point for PCT was determined. A p-value $\leq 0.05$ was considered statistically significant.

\section{RESULTS}

One hundred and seventy-one neonates, who fulfilled the study criteria, were included in the study. Among them, 87 (50.9\%) were females. Mean age of the patients was $7.5 \pm 6.6$ days. Out of 171 patients, 79 (46.2\%) neonates have low birth weight, $103(60.2 \%)$ were born at full term, only 46 (26.9\%) had history of PROM.

On blood culture, 86 (50.3\%) patients had bacterial growth, while 85 (49.7\%) patients had no growth. Median PCT and CRP level in all neonates were $1.51 \mathrm{ng} / \mathrm{ml}(0.32-10.28)$ and 2.50 $\mathrm{ug} / \mathrm{L}(1.0-30.54)$ respectively. Median PCT levels of $7.10 \mathrm{ng} / \mathrm{ml}$ (1.56-22.05) and CRPlevels of 8.81ug/L (1.50-72.28) in culture positive group were significantly higher when compared to blood culture negative group ( $p$-value $<0.001$ ). However, no significant difference was noted in TLC and PLT as shown In Tablel.

At a cut-off of PCT value of $\geq 0.5 \mathrm{ng} / \mathrm{ml}$, out of 171 neonates, 84 neonates were true positive (TP) i.e. PCT $>0.5 \mathrm{ng} / \mathrm{ml}$ and blood culture was positive as well, 25 were false positive (FP) i.e. PCT $>0.5 \mathrm{ng} / \mathrm{ml}$ but blood culture was negative, 2 were false negative (FN) i.e. PCT $<0.5$ but blood culture was positive and 60 were true negative (TN) i.e. PCT $<0.5$ and blood culture was also negative. 
Table I: Descriptive statistics of the study population.

\begin{tabular}{|c|c|c|c|c|c|c|c|}
\hline & \multicolumn{2}{|c|}{$\begin{array}{l}\text { All neonates } \\
(n=171)\end{array}$} & \multicolumn{2}{|c|}{$\begin{array}{l}\text { Blood culture positive group } \\
(n=86)\end{array}$} & \multicolumn{2}{|c|}{$\begin{array}{l}\text { Blood culture negative group } \\
\qquad(\mathrm{n}=85)\end{array}$} & \multirow[t]{2}{*}{ p-value } \\
\hline & Mean $\pm(S D)$ & Median & Mean \pm (SD) & Median & Mean \pm (SD) & Median & \\
\hline Age (days) & $7.5 \pm(6.6)$ & $\begin{array}{c}5.0 \\
(2.0-11.0)\end{array}$ & $7.7 \pm(6.7)$ & $\begin{array}{c}5.00 \\
(2.75-11.25)\end{array}$ & $7.3 \pm(6.4)$ & $\begin{array}{c}5.0 \\
(1.50-11.50)\end{array}$ & 0.513 \\
\hline $\begin{array}{l}\text { Gestational age } \\
\text { (weeks) }\end{array}$ & $35.85 \pm(3.42)$ & $\begin{array}{c}37.00 \\
(33.00-39.00)\end{array}$ & $35.06 \pm(3.51)$ & $\begin{array}{c}35.50 \\
(33.00-37.00)\end{array}$ & $36.66 \pm(3.2)$ & $\begin{array}{c}37.00 \\
(35.00-39.00)\end{array}$ & $0.001 *$ \\
\hline Birth weight $(\mathrm{Kg})$ & $2.53 \pm(0.74)$ & $\begin{array}{c}2.7 \\
(2.0-3.1) \\
\end{array}$ & $2.42 \pm(0.76)$ & $\begin{array}{c}2.30 \\
(1.90-3.02)\end{array}$ & $2.66 \pm(0.71)$ & $\begin{array}{c}2.90 \\
(2.30-3.10)\end{array}$ & $0.023 *$ \\
\hline Procalciton (ng/ml) & $10.42 \pm(19.95)$ & $\begin{array}{c}1.51 \\
(0.32-10.28)\end{array}$ & $18.16 \pm(25.0)$ & $\begin{array}{c}7.10 \\
(1.56-22.05) \\
\end{array}$ & $2.59 \pm(6.97)$ & $\begin{array}{c}0.32 \\
(0.19-1.06)\end{array}$ & $<0.001^{*}$ \\
\hline CRP (ug/L) & $26.7 \pm(49.4)$ & $\begin{array}{c}2.50 \\
(1.00-30.54)\end{array}$ & $44.4 \pm(62.6)$ & $\begin{array}{c}8.81 \\
(1.50-72.28) \\
\end{array}$ & $8.8 \pm(18.3)$ & $\begin{array}{c}1.00 \\
(1.00-6.73)\end{array}$ & $<0.001^{*}$ \\
\hline $\operatorname{TLC}\left(\times 10^{9} / \mathrm{L}\right)$ & $14.9 \pm(19.2)$ & $\begin{array}{c}11.6 \\
(8.2-16.0)\end{array}$ & $13.8 \pm(7.9)$ & $\begin{array}{c}13.2 \\
(7.8-16.8)\end{array}$ & $16 \pm(26.1)$ & $\begin{array}{c}10.9 \\
(8.7-15.5)\end{array}$ & 0.344 \\
\hline $\operatorname{PLT}\left(\times 10^{9} / \mathrm{L}\right)$ & $212 \pm(129)$ & $\begin{array}{c}213 \\
(116-308)\end{array}$ & $212.6 \pm(139)$ & $\begin{array}{c}207.5 \\
(110.5-314)\end{array}$ & $211.4 \pm(119)$ & $\begin{array}{c}219 \\
(142.5-300)\end{array}$ & 0.909 \\
\hline
\end{tabular}

Table II: Diagnostic accuracy of PCT using blood culture as gold standard with respect to age, birth weight groups, prematurity and premature rupture of membranes.

\begin{tabular}{|c|c|c|c|c|c|c|c|}
\hline & Total (n) & $\begin{array}{c}\text { Sensitivity } \\
\text { (\%) }\end{array}$ & $\begin{array}{c}\text { Specificity } \\
(\%)\end{array}$ & $\begin{array}{l}\text { PPV } \\
\text { (\%) }\end{array}$ & $\begin{array}{l}\text { NPV } \\
(\%)\end{array}$ & LR+ve/LR-ve & $\begin{array}{c}\text { Overall } \\
\text { diagnostic } \\
\text { accuracy (\%) }\end{array}$ \\
\hline All Neonates & 171 & 97.7 & 70.6 & 77.1 & 96.8 & $3.32 / 0.03$ & 84.2 \\
\hline $\begin{array}{l}\text { Age: } \\
\text { 1-7 days } \\
8-29 \text { days }\end{array}$ & $\begin{array}{c}102 \\
69\end{array}$ & $\begin{array}{l}98.2 \\
96.9\end{array}$ & $\begin{array}{l}64.6 \\
78.4\end{array}$ & $\begin{array}{l}75.7 \\
79.5\end{array}$ & $\begin{array}{l}96.9 \\
96.7\end{array}$ & $\begin{array}{l}2.77 / 0.03 \\
4.48 / 0.04\end{array}$ & $\begin{array}{l}82.4 \\
87.0\end{array}$ \\
\hline $\begin{array}{l}\text { Birth Weight: } \\
\text { Low birth weight } \\
(<2.5 \mathrm{KG}) \\
\text { Normal birth weight } \\
(\geq 2.5 \mathrm{KG})\end{array}$ & $\begin{array}{l}79 \\
92\end{array}$ & $\begin{array}{l}100.0 \\
94.3\end{array}$ & $\begin{array}{l}71.4 \\
70.2\end{array}$ & $\begin{array}{l}86.4 \\
66.0\end{array}$ & $\begin{array}{l}100.0 \\
95.2\end{array}$ & $\begin{array}{l}3.50 / 0.00 \\
3.16 / 0.08\end{array}$ & $\begin{array}{l}89.9 \\
79.4\end{array}$ \\
\hline $\begin{array}{l}\text { Prematurity: } \\
\text { Before } 36 \text { weeks } \\
\text { After } 36 \text { weeks }\end{array}$ & $\begin{array}{c}68 \\
103\end{array}$ & $\begin{array}{c}100.0 \\
95.2\end{array}$ & $\begin{array}{l}66.7 \\
72.1\end{array}$ & $\begin{array}{l}84.6 \\
70.2\end{array}$ & $\begin{array}{c}100.0 \\
95.7\end{array}$ & $\begin{array}{l}3.00 / 0.00 \\
3.42 / 0.07\end{array}$ & $\begin{array}{l}88.2 \\
81.6\end{array}$ \\
\hline $\begin{array}{l}\text { Premature rupture of } \\
\text { membranes: } \\
\text { Yes } \\
\text { No }\end{array}$ & $\begin{array}{c}46 \\
125\end{array}$ & $\begin{array}{c}100.0 \\
96.0\end{array}$ & $\begin{array}{l}40.0 \\
74.7\end{array}$ & $\begin{array}{l}85.7 \\
71.6\end{array}$ & $\begin{array}{c}100.0 \\
96.6\end{array}$ & $\begin{array}{c}1.67 / 0.0 \\
3.79 / 0.05\end{array}$ & $\begin{array}{l}87.0 \\
83.2\end{array}$ \\
\hline
\end{tabular}

Table III: Diagnostic sensitivity and specificity of PCT at various cutoff levels.

\begin{tabular}{|l|l|l|}
\hline PCT Cut-off (ng/ml) & Sensitivity (\%) & Specificity (\%) \\
\hline 0.5 & 97.7 & 70.6 \\
\hline 1 & 86 & 75.3 \\
\hline 1.5 & 77.9 & 77.6 \\
\hline 2 & 72.1 & 78.8 \\
\hline 2.5 & 66.3 & 81.2 \\
\hline 3 & 62.8 & 82.4 \\
\hline
\end{tabular}

Sensitivity of PCT with respect to age, birth weight, prematurity, PROM ranged between $94.3 \%-100 \%$, while specificity was between $40.0 \%-78.4 \%$. Overall NPV was higher than PPV making PCT better screening marker for neonatal sepsis. Overall diagnostic accuracy of PCT in this study was $84.2 \%$, while it was higher in low birth weight neonates as compared to normal birth weight neonates, 8-29 days of age and premature babies, as shown in Table II.

Receiver operating characteristic (ROC) curve analysis was employed to evaluate the performance of PCT, CRP, TLC and PLT counts against the blood culture taken as gold standard. Area under curve (AUC) for PCT was AUC: 0.869, 95\%C.I:0.82-0.92, p<0.001) which was higher than AUC for other markers of sepsis i.e. CRP (AUC 0.717, 95\% C.I:0.64-0.79, $p<0.001$ ), TLC (AUC 0.542, 95\% C.I:0.45-0.63, $p=0.344$ ) and PLT (AUC 0.495, 95\% C.I:0.41-0.58, p=0.909). Upon evaluation of diagnostic performance of PCT at various cut offs, it was noted to have maximum sensitivity at 0.5 $\mathrm{ng} / \mathrm{ml}$, while specificity reached its peak at a cut off value of $3.0 \mathrm{ng} / \mathrm{ml}$ as shown in Table III. 


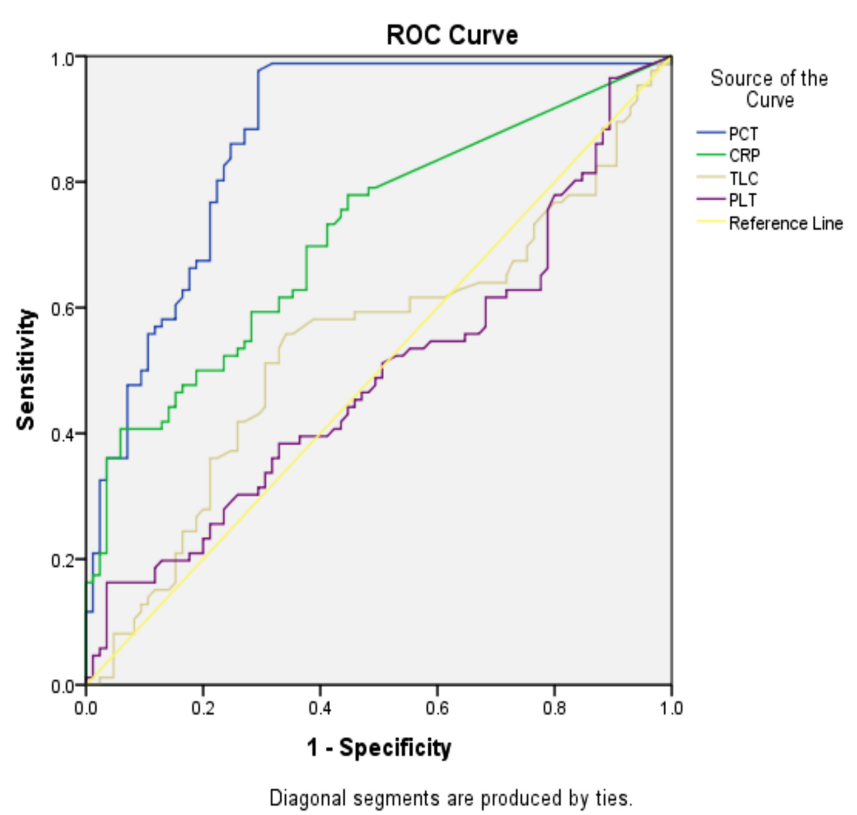

Figure 1: ROC-AUC analysis of PCT, CRP, WBC and PLT against blood culture as gold standard.

\section{DISCUSSION}

Neonatal sepsis is recognised as a major cause of mortality and morbidity among neonates. Signs and symptoms of sepsis are very non-specific, often overlapping with other non-infectious systemic inflammatory conditions. As the course of management varies widely between sepsis and other systemic inflammatory conditions, it is imperative to differentiate the two conditions as soon as possible at presentation. In this study, PCT was evaluated as an early and effective marker for diagnosis of sepsis, using blood culture as gold standard test. PCT was evaluated is considered helpful as its results are available within two hours, thus helping in early identification of disease condition and its timely management. In Pakistan, there is scarcity of data on serum PCT and its association with neonatal sepsis. Some studies show reservations about ambiguity on the findings and the subject requires further studies to strengthen the evidence. $^{17,18}$

This study included a sizeable number of neonates with clinical suspicion of neonatal sepsis, they were investigated for serum PCT levels and blood culture; out of which, 86 (50.3\%) were diagnosed as having sepsis proven by positive blood culture as compared to $90(47 \%)$ in a study carried out in 2016 by Dipmala Das et al. ${ }^{19}$

Frequency of early onset sepsis in this study is very high, 54 $(62.8 \%)$ were identified as of the early onset sepsis type (1-7 days of age), and 32 (37.2\%) were identified as of the late onset type (8-28 days of age). While, according to a case control study performed on 1-3 days old neonates conducted by Israr et al. in 2020, reported that out of 19 babies admitted in NICU for sepsis, 18 babies have raised PCT level on cord blood sample which gives support to this study in the context of early onset sepsis. ${ }^{20}$

In this study, PCT had over all sensitivity of $97.7 \%$, specificity $70.6 \%$, PPV $77.1 \%$, and NPV $96.8 \%$. The LR+ve and LR-ve were found to be 3.32 and 0.03 , respectively. Diagnostic accuracy of PCT in this study was found to be $84.2 \%$. The high negative predictive value provides a strong reassurance that if PCT value is $<0.5 \mathrm{ng} / \mathrm{ml}$, the likelihood of sepsis is very low. These findings are supplemented by a similar study conducted by Nelly et al, which reported sensitivity of $100 \%$, specificity $85.7 \%$, PPV $97.2 \%$, and NPV $100 \% .{ }^{21}$ The findings of the previous study, done by Das et al., were also consistent with this study. ${ }^{19}$ Furthermore, several multinational studies from United States, Europe and Asia reported the sensitivity from $76 \%-100 \%$, and specificity from $52 \%-88 \% .{ }^{21,22}$

The PCT cut-off used in neonatal ICUs, varies throughout the world. ${ }^{17,19}$ Based on ROC curve analysis, the optimal cut-off of $0.5 \mathrm{ng} / \mathrm{ml}$ showed $97.7 \%$ sensitivity and $70.6 \%$ specificity. Israr et al. calculated PCT cut-off $0.4 \mathrm{ng} / \mathrm{ml}$ through their study, which was approximately the same as used by this study. Thus, the cut-off value of $0.5 \mathrm{ng} / \mathrm{ml}$ for PCT can be used for screening and diagnosis of neonatal sepsis as it indicates a two-old probability of sepsis. ${ }^{20}$

The limitations of this study included lack of serial measurements of PCT, prognostic value of various levels of PCT at the time of presentation, and identification of specific organisms causing neonatal sepsis. Sample size in this study can be improved upon by conducting larger multicenter research on this same topic.

\section{CONCLUSION}

This study validates PCT as a good diagnostic biomarker for the diagnosis of neonatal sepsis. Early and appropriate antibiotic therapy can be initiated without waiting for the results of culture and sensitivity reports to reduce the mortality and other complications.

It can be safely concluded that addition of PCT as a part of laboratory workup for suspected neonatal sepsis patients will greatly improve patient outcomes.

\section{ETHICAL APPROVAL:}

Permission from the Ethical Committee of the Ziauddin University Hospital was taken.

\section{PATIENTS' CONSENT:}

Parents/guardians of the patients were informed about study purpose and consents were taken.

\section{CONFLICT OF INTEREST:}

The authors declared no conflict of interest.

\section{AUTHORS' CONTRIBUTION:}

$\mathrm{AH}$ : Conception, design of the work, acquisition, analysis, interpretation of data for the work, drafting work and final 
approval.

SR: Analysis, interpretation of data for the work.

UA: Conception, critical review of intellectual content and final approval of the version.

AMZ: Conception, design of the work, the acquisition, critical review of intellectual content and final approval of the work.

ES: Critical review of intellectual content and final approval of the work.

\section{REFERENCES}

1. Kőszegi T. Advances in the diagnosis of sepsis. eJIFCC 2017; 28(2):99-103.

2. Gyawali B, Ramakrishna K, Dhamoon A. Sepsis: The evolution in definition, pathophysiology, and management. SAGE Open Med 2019; 7:1-13.

3. Gul F, Arslantas M, Cinel I, Kumar A. Changing Definitions of Sepsis. Turk J Anaesthesiol Reanim 2017; 45(3):129-38.

4. Greenwood D. Antibiotic and chemotherapy. 8th ed. United States: Oxford university press; 2003. 518 p.

5. Pontrelli G, De Crescenzo F, Buzzetti R, Jenkner A, Balduzzi S, Carducci FC, et al. Accuracy of serum procalcitonin for the diagnosis of sepsis in neonates and children with systemic inflammatory syndrome: a meta-analysis. BMC Infect Dis 2017; 17(1):302-14.

6. Li X, Ding X, Shi P, Zhu Y, Huang Y, Li Q, et al. Clinical features and antimicrobial susceptibility profiles of culture-proven neonatal sepsis in a tertiary children's hospital, 2013 to 2017. Medicine 2019; 98(12): e14686.

7. Jehan I, Harris H, Salat S, Zeb A, Mobeen N, Pasha O, et al. Neonatal mortality, risk factors and causes: a prospective population-based cohort study in urban Pakistan. Bull World Health Organ 2009; 87(2):130-8.

8. Hisamuddin E, Hisam A, Wahid S, Raza G. Validity of Creactive protein (CRP) for diagnosis of neonatal sepsis. PakJ Med Sci 2015; 31(3):527-31.

9. Iroh Tam $P$, Bendel C. Diagnostics for neonatal sepsis: Current approaches and future directions. Pediatr Res 2017; 82(4):574-83.

10. Rashwan N, Hassan M, Mohey El-Deen Z, Ahmed A. Validity of biomarkers in screening for neonatal sepsis A single center -hospital based study. Pediatr Neonatol
2019; 60(2):149-55.

11. Levy M, Evans L, Rhodes A. The surviving sepsis campaign bundle: 2018 update. Intensive Care Med 2018; 44(6):925-8.

12. Vijayan A, Vanimaya, Ravindran S, Saikant R, Lakshmi $\mathrm{S}$, Kartik R, et al. Procalcitonin: A promising diagnostic marker for sepsis and antibiotic therapy. J Intensive Care 2017; 5:51.

13. Rogic D, Juros GF, Petrik J, Vrancic AL. Advances and pitfalls in using laboratory biomarkers for the diagnosis and management of sepsis. eJIFCC 2017; 28(2): 114-21.

14. Trasy D, Molnar Z. Procalcitonin-assisted antibiotic strategy in sepsis. eJIFCC 2017; 28(2): 104-13.

15. Ahmed S, Siddiqui I, Jafri L, Hashmi M, Khan A, Ghani F. Prospective evaluation of serum procalcitonin in critically ill patients with suspected sepsis- experience from a tertiary care hospital in Pakistan. Ann Med Surg 2018; 35:180-4.

16. Meisner M. Update on procalcitonin measurements. Ann Lab Med 2014; 34(4):263-73.

17. Sager R, Kutz A, Mueller B, Schuetz P. Procalcitonin-guided diagnosis and antibiotic stewardship revisited. BMC Med 2017; 15(1):15.

18. Lopez Sastre JB, Perez Solís D, Roques Serradilla V, Fernandez Colomer B, Coto Cotallo GD, Krauel Vidal X, et al. Procalcitonin is not sufficiently reliable to be the sole marker of neonatal sepsis of nosocomial origin. BMC Pediatr 2006; 18(6): 16.

19. Das D, Barua N, Sharma JN. Evaluation of blood culture and serum procalcitonin for diagnosis of septicaemia in paediatric patients. Indian J Microbiol Res 2016; 3(3): 250-4.

20. Israr S, Hayat A, Mahmood T, Majeed N, Hussain S, Tehseen S. Comparison of procalcitonin and hematological ratios in cord blood as early predictive marker of neonatal sepsis. Pak Armed Forces Med J 2020; 70(3):824-9.

21. Nelly N, Tjipta G, Hakimi H, Lubis B. Procalcitonin as a diagnostic tool for bacterial neonatal sepsis. Paediatr Indones 2015; 55(5):268-72.

22. Nellis M, Pon S, Giambrone A, Coleman N, Reiss J, Mauer $E$, et al. The diagnostic accuracy of serum procalcitonin for bacteremia in critically ill children. Infect Dis Clin Pract 2016; 24(6):343-7. 